\title{
Competency-based Medical Education in India
}

\author{
Dhastagir Sultan Sheriff
}

\begin{abstract}
Indian medical education was structured and believed in summative assessment. Competency-based medical education (CBME), on the other hand, is to train the learner to become a holistic primary care physician. Competency-based medical education's competencies are so designed to bridge the gap between theoretical aspects with practical clinical skills, tempered with compassion and empathy to become a health professional guided by a value system having sound ethical principles.
\end{abstract}

Keywords: Health, India, Medical education.

Annals of SBV (2020): 10.5005/jp-journals-10085-8125

"The primary goal of undergraduate medical education is to train and produce Physicians who will serve the needs and expectations of a patient. Keeping this view in mind a change in medical education is envisaged and implemented. Such a change requires a short reflection on what type of medical education is now in practice and how it can be modified to suit the needs of patient."

Flexner's model emphasized that medical education needs to develop the capacity to think and problem-solve scientifically. Osler proposed that clinicians allow every student's inborn sense of moral duty to blossom on the wards. In other words, Osler wanted the student to spend more time in the wards, whereas Flexner wanted problem solved skills to be based on scientific analyzes. ${ }^{1}$

According to the Accreditation Council of Graduate Medical Education, the USA identified six domains that will enable the physician to be competent. These are patient care, medical knowledge, practice-based learning, interpersonal relationship, communication skills, professionalism, and system-based practice. British Medical Council regarded a doctor as a scholar, a scientist, a practitioner, and a researcher. ${ }^{2-4}$

Based on these studies and the need to change the concept of medical education, the Medical Council of India introduced competency-based medical education (CBME). It was felt that basic clinical skills as well as soft skills like communication, doctor-patient relationship, ethics, and professionalism must be stressed in the promotion of graduate medical education. ${ }^{5}$

In structure-based medical education, the driving force is curriculum content and the acquisition of knowledge. The teacher became the most important cog in the wheel of medical education. The core concept in such a teacher-centric education is to attain a strong knowledge base with little attention toward training in the application and development of clinical as well as soft skills. The method of assessment was summative and time-restricted.

The shift in medical education is toward shared responsibility in the learning process, self-directed, and collaborative learning. The emphasis is on learner-centric leading to acquire clinical skills and certification. Formative assessment became an integral part of the learning process stressing the need to assess continuously until the learner gets proficient in the skill or knowledge taught. ${ }^{5}$

Competency-based medical education focuses on the application of knowledge to enhance the clinical skills of the learner. The learner is exposed to multiple objectives to learn by
Department of Biochemistry, Faculty of Medicine, Benghazi University, Benghazi, Libya

Corresponding Author: Dhastagir Sultan Sheriff, Department of Biochemistry, Faculty of Medicine, Benghazi University, Benghazi, Libya, Phone: +2309003159147, e-mail: drdsheriff@gmail.com

How to cite this article: Sheriff DS. Competency-based Medical Education in India. Ann SBV 2020;9(2):39-41.

Source of support: Nil

Conflict of interest: None

direct observation applying different criteria of assessment. Until the learner succeeds in completing the competency, the learner is not certified. The learner is made to repeat learning the same competency to achieve success.

Competency-based medical education relies on greater accountability, flexibility and, is student-centric.

\section{What is Competency-based Medical EdUCATION?}

It is an outcome-based approach to design, for implementation, assessment, and evaluation of medical education using an organized framework of competencies. ${ }^{6}$

\section{What are the Suggested Steps to be Taken FOR IMPLEMENTING CBME}

- Competencies are determined and aligned with the mission and vision.

- The learning outcomes are stated and communicated to the learner.

- An environment to achieve the outcome has to be created.

- Achievement of the outcome is to be ascertained and documented.

It is suggested to have a system that will have proof of acquisition of selected competencies and achievement of that outcome. This has to be followed by an assessment (of a determined standard periodic evaluation (internal assessment)), document the attainment of predetermined skills, attitudes, and values referred

\footnotetext{
(c) The Author(s). 2020 Open Access This article is distributed under the terms of the Creative Commons Attribution 4.0 International License (https:// creativecommons.org/licenses/by-nc/4.0/), which permits unrestricted use, distribution, and non-commercial reproduction in any medium, provided you give appropriate credit to the original author(s) and the source, provide a link to the Creative Commons license, and indicate if changes were made. The Creative Commons Public Domain Dedication waiver (http://creativecommons.org/publicdomain/zero/1.0/) applies to the data made available in this article, unless otherwise stated.
} 
to in the curriculum developed with core competencies. Medical Council of India has come out with a referral that delineates in detail the topics and outcomes to be achieved by the undergraduate medical education (Refer $\mathrm{MCl}$ Booklet for Competencies related to different subjects). ${ }^{7}$

The booklet gives full details regarding all the competencies that need to be followed and how these competencies to be taught with a focus on student centered learning. It is suggested to keep the $\mathrm{MCl}$ booklet as a guide and create such competencies by every medical college that is involved in imparting undergraduate medical education. It is suggested that following types of verbs can be used to create competencies: (MCl Booklet). ${ }^{7}$

\begin{tabular}{lll}
\hline $\begin{array}{l}\text { Active verbs used for } \\
\text { knowledge domain }\end{array}$ & Active verbs used for skill & Affective \\
\hline Enumerate & Identify & Counsel, inform \\
List & Demonstrate & \\
Describe & Perform under supervision & \\
Discuss & Perform independently & \\
Differentiate & Document & \\
Define & Present \\
Classify & Record \\
Choose & Interpret \\
Elicit & \\
Report & \\
\hline
\end{tabular}

Taking these factors in mind, one can redefine a competency as the capability to apply or use a set of related knowledge, skills, and abilities required to successfully perform "critical work functions" or tasks in a defined work setting.

It may require the application of measurable skills, abilities, and personality traits. Therefore, competency is more than knowledge and skills.

The core values of imparted will be responsibility, decisionmaking, communication, leadership, trustworthiness, and ethics.

The following Table given by $\mathrm{MCl}$ explains how to enter the competencies, distribute them in various domains, domain to which the competency is related, which competencies to be demonstrated and which to be performed and certified. It also emphasized vertical and horizontal integration of various subjects at different but appropriate levels. ${ }^{7}$

\begin{tabular}{|c|c|c|c|c|}
\hline Say: PY 1.1. & Competency & Domain & $\mathrm{K} / \mathrm{KH} / \mathrm{SH} / \mathrm{P}$ & Core \\
\hline $\begin{array}{l}\text { PY-subject- } \\
\text { physiology }\end{array}$ & $\begin{array}{l}\text { Describe the / } \\
\text { Structure and } \\
\text { functions of }\end{array}$ & $\begin{array}{l}\text { K. } \\
\text { knowledge }\end{array}$ & $\begin{array}{l}\text { Knows, knows } \\
\text { how, shows } \\
\text { how, performs }\end{array}$ & $\begin{array}{l}\text { Must } \\
\text { know }\end{array}$ \\
\hline $\begin{array}{l}\text { 1-Topic } \\
\text { number }\end{array}$ & $\begin{array}{l}\text { Elicit document } \\
\text { and present a } \\
\text { medical his- } \\
\text { tory that helps } \\
\text { delineate the }\end{array}$ & S. skill & & \\
\hline $\begin{array}{l}\text { 1-Running } \\
\text { number }\end{array}$ & & & & \\
\hline
\end{tabular}

The first page of the module with competencies could be Name of the Medical College

10 Semesters (5 years) MBBS Program

Degree Awarding body_University of...
MBBS Program - Subject: code and abbreviation

Subject Information Pack (Module information pack) How Many

Modules with competencies listed

Name of the Subject:

Subject code:

Subject information pack (Module Information pack)

Name of the subject:

Subject code:

Semesters in which teaching and learning are programmed:

The number of hours supervised contact with the student:

Name of the head of the faculty of this subject:

Assessment (examination): at the end of the semester as part of the professional examination

Assessment pattern and marks allocated/clinical examinationmarks

K-knows; KH: knows How; Core: must know; D-demonstrate, Core-y

Points to remember while preparing the module:

While preparing the module with competencies described one has to take into consideration the following:

- The pattern of syllabus suggested by the regulatory body followed by a specific college.

- The requirement of the university to which the college is affiliated.

- Listing specific subject module with the list of competencies semester wise including core competencies and other skills to be developed.

- The examination pattern to be followed and distribution of marks to be given for theory and practical (clinical).

- The question paper is set according to the competencies.

- If the question paper involves an essay, short essay, and multiple choice questions uniform pattern to be followed with marks distribution, the standardized format of MCQs (avoiding recall of knowledge or knows how).

- For a college or university in the process of evolving the first year of the course or the I to IV semester exam may have MCQs related to recall of knowledge (two-third) and one-third will be to test the application of learned competency.

- The practical or clinical exam could be based on objective structured practical examination (OSPE) with a fixed no of stations designed to check the performance skill as well as the clinical practical skill of the learner. Each station with a fixed time limit needs to give a gap of rest for 5-10 minutes following halfway through the stations.

The emphasis now is laid on a formative continuous assessment that will help check whether the student has attained the capacity to apply the competency learned in an actual clinical situation. The curriculum designed by the institution dictates the core competencies to be learned. The intended outcome is to see that the learner at the end of the course has developed into a clinician with a greater understanding of the patient's needs capable of providing preventive, promotive, curative, palliative, and holistic care. The medical graduate program designed must help the student to develop a capacity to be a team leader with analytical skills. The training has to help the learner develop adequate communication skills so that the learner could convey information to the patient, family, colleagues, and community in a manner that suits the context and environment (Tables 1 to 3 ). 
Table 1: Model table for writing and placing your competencies

\begin{tabular}{|c|c|c|c|c|c|c|c|c|c|}
\hline No & Competencies & Domain & $K / K H / P$ & Core- $Y$ & $\begin{array}{l}\text { Suggested } \\
\text { teaching } \\
\text { method }\end{array}$ & $\begin{array}{l}\text { Suggested } \\
\text { assessment } \\
\text { method }\end{array}$ & $\begin{array}{l}\text { No require to } \\
\text { certify }\end{array}$ & $v$ & $h$ \\
\hline
\end{tabular}

PY 1.1

Table 2: Distribution of marks

\begin{tabular}{lllll}
\hline Theory & & Practical & \\
\hline Theory Viva Internal assessment & Theory total & Practical/clinical Internal assessment & $\begin{array}{l}\text { Practical/clinical Grand total } \\
\text { total }\end{array}$ \\
\hline
\end{tabular}

Suggested Reference Books: (All must be latest editions).

Table 3: Format for preparing the curriculum with competencies listed

\begin{tabular}{llll}
\hline Module no Topic/unit & Competencies & Domain & Weightage\% \\
\hline & $\mathrm{K}, \mathrm{KH}$, skill, \\
& core, dem- \\
& onstrate/ \\
& performs \\
\hline
\end{tabular}

The learner is made to understand that learning is a continuous process requiring a commitment for life-long learning to improve clinical skills and to update the knowledge base. ${ }^{8-10}$

\section{Conclusion}

Flexner's model emphasized developing the capacity of the learner to think and attain problem-solving skills in a scientific manner. On the other hand, Osler believed in bedside teaching. In other words, Osler wanted the student to spend more time in the wards whereas Flexner wanted the physician to develop problem-solving skills based on scientific analyzes. ${ }^{1}$

According to the Accreditation Council of Graduate Medical Education, the USA identified six domains of learning to be imparted to make the physician competent. The core values to be learned are patient care, medical knowledge, practice-based learning, interpersonal relationship, communication skills, professionalism, and system-based practice.

British Medical Council regarded a doctor as a scholar, a scientist, a practitioner, and a researcher. Indian Medical education was structured and believed in summative assessment. Competency-Based Medical Education, on the other hand, is to train the learner to become a holistic primary care physician. Development of competency involves the habitual and judicious use of communication, knowledge, technical skills, clinical reasoning, emotions, values, and reflection in daily practice for the benefit of the individual and the community being served.

Implementation of CBME requires full support from the management and administration. Faculty must be trained on various aspects of CBME. There needs to be a social contract or commitment from the faculty members to follow the objectives of CBME. This needs to be supported by a structured and well-organized curriculum. A continuous formative assessment and assessment tools have to be in place to evaluate the competencies learned. Constructive and descriptive feedback and reflection on the competencies imparted need to be recorded. Financial support from the management is essential to implement and fulfill the learning objectives of CBME. ${ }^{11-16}$

Competency-based medical education's competencies are so designed to bridge the gap between theoretical aspects with practical clinical skills, tempered with compassion and empathy to become a health professional guided by a value system having sound ethical principles.

\section{References}

1. Frank JR, Mungroo R, Ahmad Y, Wang M, De Rossi S, Horsley T. Towarda definition of competency-based education in medicine: a systematic review of published definitions. Med Teach 2010;32(8):631-637. DOI: 10.3109/0142159X.2010.500898.

2. Swing SR. The ACGME outcome project: retrospective and prospective. Med Teach 2007;29(7):648-654. DOI: 10.1080/01421590701392903.

3. General Medical Council. Tomorrow's Doctors: Education Outcomes and Standards for Undergraduate Medical Education. Available from: http://www.gmc-uk.org/Tomorrow_s_Doctors_1214.pdf_48905759. pdf. [Last accessed on 2016 May 16].

4. Medical Council of India Regulations on Graduate Medical Education; 1997. Available from: http://www.mciindia.org/Rules-andRegulation/GME_REGULATIONS.pdf. [Last accessed on 2016 May 16].

5. Batalden P, Leach D, Swing S, Dreyfus H, Dreyfus S. General competencies and accreditation in graduate medical education. Health Aff (Millwood) 2002;21(5):103-111. DOI: 10.1377/hlthaff.21.5.103.

6. Hurtubise L, Roman B. Competency-based curricular design to encourage significant learning. Curr Probl Pediatr Adolesc Health Care 2014;44(6):164-169. DOI: 10.1016/j.cppeds.2014.01.005.

7. Medical Council of India. Vision 2015. New Delhi: Medical Council of India; 2011. Available from: http://www.mciindia.org/tools/ announcement/MCI_booklet.pdf. [Last accessed on 2016 May 16].

8. Harris P, Snell L, Talbot M, Harden RM. Competency-based medical education: implications for undergraduate programs. Med Teach 2010;32(8):646-650. DOI: 10.3109/0142159X.2010.500703.

9. Holmboe ES, Sherbino J, Long DM, Swing SR, Frank JR. The role of assessment in Competency-based medical education. Med Teach 2010;32(6):676-682. DOI: 10.3109/0142159X.2010.500704.

10. Vinten-Johansen P, Riska E. New Oslerians and real flexnerians: the response to threatened professional autonomy. Int J Health Serv 1991;21(1):75-108. DOI: 10.2190/7EDU-HA2D-Q39L-D70W.

11. Caverzagie KJ, Nousiainen MT, Ferguson PC, Ten Cate O, Ross S, Harris KA, et al. Overarching challenges to the implementation of competency-based medical education. Med Teach 2017;39(6):588593. DOI: 10.1080/0142159X.2017.1315075.

12. Shah N, Desai C, Jorwekar G, Badyal D, Singh T. Competency-based medical education: an overview and application in pharmacology. Indian J Pharmacol 2016;48(SuppI 1):S5-S9. DOI: 10.4103/02537613.193312.

13. Kiguli-Malwadde E, Olapade-Olaopa EO, Kiguli S, Chen C, Sewankambo NK, Ogunniyi AO, et al. Competency-based medical education in two sub-saharan african medical schools. Adv Med Educ Pract 2014;5:483-489. DOI: 10.2147/AMEP.S68480.

14. Cate OT. A primer on entrustable professional activities. Korean J Med Educ 2018;30(1):1-10. DOI: 10.3946/kjme.2018.76.

15. Timmerman AA, Dijkstra J. A practical approach to programmatic assessment design. Adv Health Sci Educ Theory Pract 2017;22(5): 1169-1182.

16. Ananthakrishnan N, Karthikeyan P, Pulimoottil DT, Jaganmohan R, Adkoli BV, Ravishanker M, et al. SBV model of competencybased learning and training for post-graduate education. Ann SBV 2017;6(1):5-10. DOI: 10.5005/jp-journals-10085-6102. 